\title{
School Distribution as Keep-Up Strategy to Maintain Universal Coverage of Long-Lasting Insecticidal Nets: Implementation and Results of a Program in Southern Tanzania
}

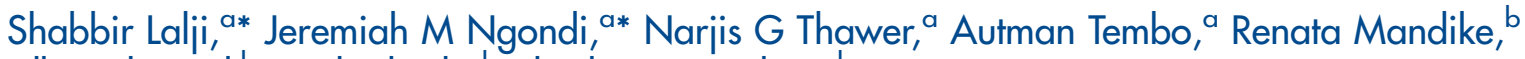
Ally Mohamed, ${ }^{b}$ Frank Chacky, ${ }^{b}$ Charles D Mwalimu, ${ }^{b}$ George Greer, ${ }^{c}$ Naomi Kaspar, ${ }^{c}$ Karen Kramer, ${ }^{d}$ Bertha Mlay, ${ }^{e}$ Kheri Issa, ${ }^{e}$ Jane Lweikiza, ${ }^{e}$ Anold Mutafungwa, ${ }^{a}$ Mary Nzowa, ${ }^{a}$ Ritha A Willilo, ${ }^{a}$ Waziri Nyoni, ${ }^{f}$ David Dadi, ${ }^{f}$ Mahdi M Ramsan, ${ }^{a}$ Richard Reithinger, ${ }^{9}$ Stephen M Magesa ${ }^{a}$

A school-based net distribution program, piloted in the Southern Zone of Tanzania to sustain $\geq 80 \%$ universal net coverage previously attained through mass campaigns, successfully issued nets to nearly all eligible students and teachers. Keys to success included:

- Effective collaboration between the Ministry of Health, local government, and implementing partners

- Social mobilization to sensitize the community about the importance of net use

- Development of a mobile application to facilitate data collection and analysis

\begin{abstract}
Tanzania successfully scaled up coverage of long-lasting insecticidal nets (LLINs) through mass campaigns. To sustain these gains, a school-based approach was piloted in the country's Southern Zone starting in 2013, called the School Net Program 1 (SNP1). We report on the design, implementation, monitoring, and outputs of the second round (SNP2) undertaken in 2014. SNP2 was conducted in all schools in Lindi, Mtwara, and Ruvuma regions, targeting students in primary (Standards 1, 3, 5, and 7) and secondary (Forms 2 and 4) schools and all teachers. In Lindi region, 2 additional classes (Standards 2 and 4) were targeted. LLIN distribution data were managed using an Android software application called SchoolNet. SNP2 included 2,337 schools, 473,700 students, and 25,269 teachers. A total of 5,070 people were trained in LLIN distribution (487 trainers and 4,583 distributors), and 4,392 (434 ward and 3,958 village) community change agents undertook sensitization and mobilization. A total of 507,775 LLINs were distributed to schools, with 464,510 (97.9\% of those registered) students and 24,206 (95.8\% of those registered) school teachers receiving LLINs. LLIN ownership and use is expected to have increased, potentially further reducing the burden of malaria in the Southern Zone of Tanzania.
\end{abstract}

\footnotetext{
a RTI International, Dar es Salaam, Tanzania.

${ }^{b}$ Ministry of Health and Social Welfare, National Malaria Control Programme, Dar es Salaam, Tanzania.

'U.S. President's Malaria Initiative/U.S. Agency for International Development, Dar es Salaam, Tanzania.

${ }^{\mathrm{d}}$ Swiss Tropical and Public Health Institute, Dar es Salaam, Tanzania.

e Tanzania Red Cross Society, Dar es Salaam, Tanzania.

fJohns Hopkins Center for Communication Programs, Dar es Salaam, Tanzania.

${ }^{9}$ RTI International, Washington, DC, USA.

* Co-first authors.

Correspondence to Jeremiah M Ngondi (jngondi@rti.org).
}

\section{BACKGROUND}

ass distribution of insecticide-treated nets, spe1 cifically long-lasting insecticidal nets (LLINs), is an effective vector control intervention to prevent malaria $^{1,2}$ and has been associated with large reductions in malaria morbidity and mortality. ${ }^{2}$ The use of LLINs in sub-Saharan Africa has increased in the past decade to reach $80 \%$ universal coverage (defined as 1 LLIN per 2 people in a household). ${ }^{3-5}$ Since 2000, the Tanzania National Malaria Control Programme (NMCP) has led the National Insecticide Treated Nets 
(NATNETS) Programme to scale up LLIN distribution and use in Tanzania. NATNETS introduced the Tanzania National Voucher Scheme (TNVS) to provide pregnant women and infants with LLINs Not all eligible people in Tanzania received LLINs through the voucher program, either because they did not attend health facilities or did not redeem vouchers. at highly discounted prices. ${ }^{6,7}$ The TNVS was successful in distributing LLINs to pregnant women and infants; however, not all eligible people were accessing health facilities to benefit from the program and not all people attending health facilities redeemed their vouchers. ${ }^{8-10}$

To ensure that the entire population (including those not covered by the TNVS) would have access to LLINs, 2 LLIN mass campaigns were implemented: (1) the children under 5 years of age catch-up campaign (U5CC) in 2009 and (2) the universal coverage campaign in 2011.11 Between 2009 and 2011, these campaigns distributed approximately 27 million LLINs, in addition to more than 3 million nets delivered through the TNVS. ${ }^{11-13}$ The TNVS, U5CC, and universal coverage campaign were successful in dramatically increasing LLIN ownership in Tanzania. Household net ownership increased from 38\% in 2007 to more than $85 \%$ in 2011, and use of LLINs increased from $25 \%$ in 2007 to $63 \%$ in 2011 . $^{14}$

\section{The Ministry developed a keep- up strategy in schools to complement the voucher scheme.}

To maintain at least $80 \%$ universal coverage of LLINs, the Ministry of Health and Social Welfare developed a keep-up strategy in schools to complement the TNVS. Keep-up strategies focus on long-term, continuous distribution through channels such as schools, health facilities, community initiatives, and the private sector; catchup strategies are periodic mass distribution campaigns. NATNETS assessed all possible keepup options and determined that a combined approach including the TNVS and school-based distribution, involving both push and pull systems, was the most cost-effective and efficient keep-up strategy for Tanzania. ${ }^{12,15-17}$ Because school enrollment in Tanzania is high and teachers can easily facilitate and manage the delivery of LLINs, school-based distribution of LLINs can be an effective strategy to reach many households. $^{18}$

In 2013, the NMCP and partners piloted the first round of the School Net Program (SNP1) to distribute LLINs in the Southern Zone of Tanzania (Lindi, Mtwara, and Ruvuma regions). Each student in Standards 1, 3, 5, and 7 of primary schools, and Forms 2 and 4 of secondary schools, received an LLIN to take home. A total of 421,285 students (83\% of those eligible) received LLINs. ${ }^{19}$ The assumption behind this strategy was that as the children moved through the school system, they would bring home a new LLIN every 2 years, which would be redistributed within the household or community. The pilot program demonstrated that it was feasible to rapidly and equitably distribute large quantities of LLINs through schools to the community. Household ownership of at least 1 LLIN increased by almost 17\% compared with an area not covered under SNP1. ${ }^{20}$ Use of LLINs among older children and adolescents also increased.

We describe here the design, implementation, monitoring, and outputs of the second round of the School Net Program (SNP2), conducted in 2014.

\section{METHODS}

\section{Study Setting}

Figure 1 shows a map of Tanzania with the locations of schools in the Southern Zone (Lindi, Mtwara, and Ruvuma regions) and 19 districts where SNP2 was implemented. In 2012, the total populations by region were 864,652 in Lindi; $1,270,854$ in Mtwara; and 1,376,891 in Ruvuma. ${ }^{21}$ In 2011, the prevalence of malaria among children under 5 years of age ranged from 12\% in Ruvuma and $17 \%$ in Mtwara to $26 \%$ in Lindi. ${ }^{14}$ In 2010, the gross enrollment ratio, which refers to the total number of students of any age enrolled in school expressed as a percentage of the official school-age population, was $94.8 \%, 102.5 \%$, and $106.6 \%$ for primary schools and $11.1 \%, 31.2 \%$, and $33.6 \%$ for secondary schools in Lindi, Mtwara, and Ruvuma, respectively. $^{22}$ The national average gross enrollment ratio was estimated at $99.0 \%$ and $31.8 \%$ for primary and secondary schools, respectively.

\section{Study Design}

SNP2 aimed to increase access to LLINs and maintain at least $80 \%$ coverage in the 3 regions by distributing LLINs free of charge to primary and secondary school students and teachers. Teachers were included as beneficiaries in SNP2 because there was an excess supply of LLINs from SNP1. In Lindi, an additional 2 grades (Standards 2 and 4) were targeted for LLIN distribution to reduce the expected remaining stock. As in SNP1, each student from Standards 1, 3, 5, and 7 and Forms 2 and 4 in Mtwara and Ruvuma received 1 LLIN.

\section{Partnership, Coordination, and Planning}

An SNP task force, chaired by the NMCP, was created to oversee the implementation of SNP2 
FIGURE 1. Locations of Schools Implementing the Second Round of the School Net Program (SNP2) in the Southern Zone of Tanzania, 2014

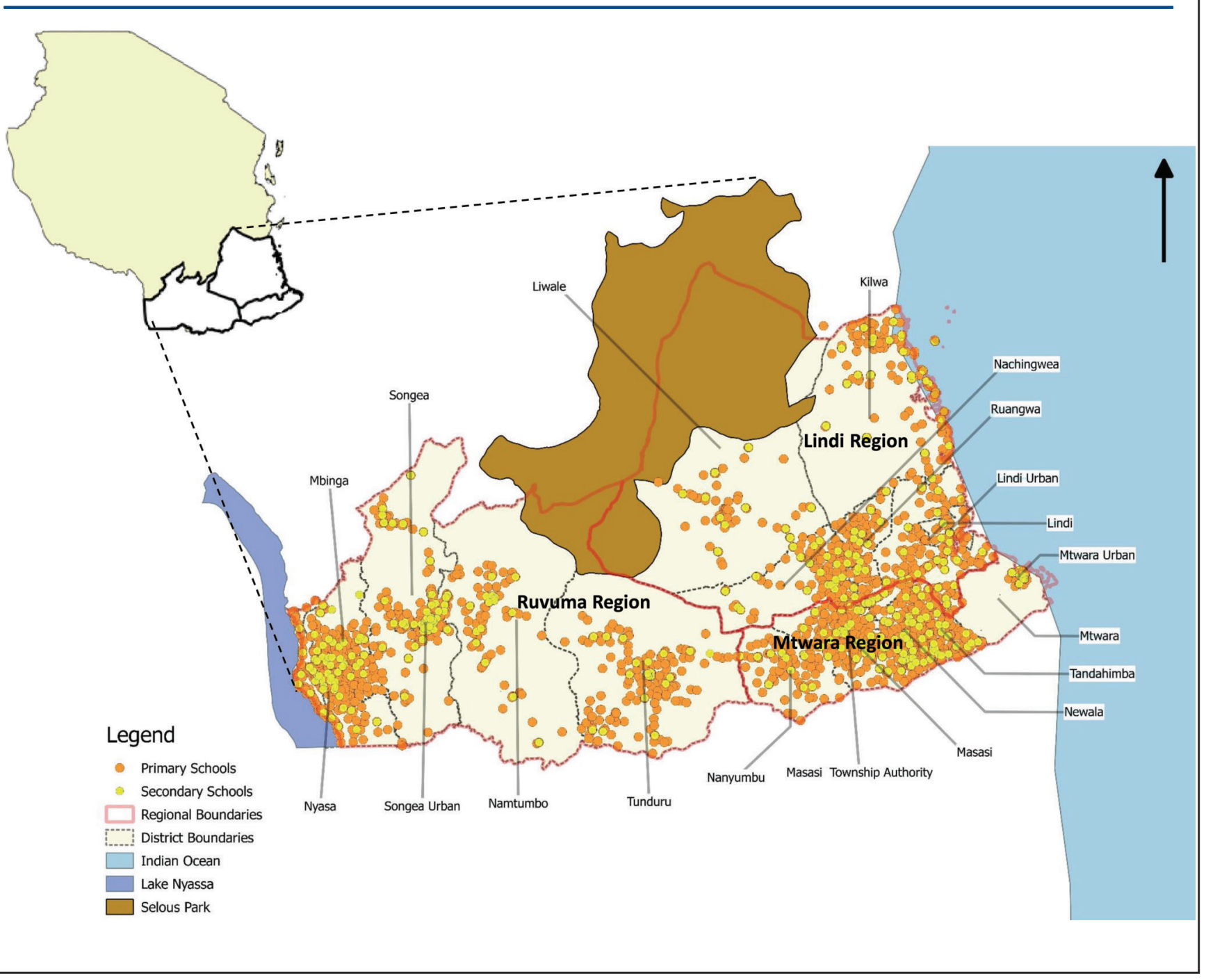

(Box). The task force played a key role in the planning, coordination, and implementation of SNP2. It ensured that LLIN distribution aligned with the NMCP's LLIN strategy and that partners were involved in key implementation decisions. It also took into account the recommendations, experiences, and lessons learned from SNP1. Advocacy meetings were held before LLIN distribution at national, regional, and district levels. Subcommittees were formed to plan specific activities, including LLIN quantification and logistics, training, social mobilization, and monitoring and evaluation (M\&E).

\section{LLIN Quantification}

Before the SNPl pilot, we used the NetCALC Planning Tool (www.vector-works.org/resources/ netcalc-planning-tool) to estimate the quantity of nets required to maintain at least $80 \%$ universal coverage in the Southern Zone of Tanzania. ${ }^{12}$ For SNP2, the number of students attending each school was estimated using SNPl registration records. We also obtained data from the district education department on the number of students and teachers in each school. Data were compared and verified to determine if there were any discrepancies. Data for eligible classes and teachers 


\section{BOX. Members of the School Net Program 2 (SNP2) Task Force}

Members of the SNP2 task force included representatives from the:

- National Malaria Control Programme

- Ministry of Health and Social Welfare School Health Program

- Ministry of Education and Vocational Training

- Prime Minister's Office Regional Authority and Local Government

- Swiss Tropical and Public Health Institute's NETCELL project

- U.S. President's Malaria Initiative

- World Health Organization

- Johns Hopkins Center for Communication Programs

- U.S. Peace Corps

- Mennonite Economic Development Associates

- RTI International

- Tanzania Red Cross Society

- Population Services International

- John Snow, Inc.

\section{A tablet-based application called SchoolNet} enabled real-time data collection from schools on LLIN issuance. in each school were used to estimate the number of LLINs to deliver to each school. A contingency amount of 3\% of the overall number of estimated LLINs for each school was also included.

\section{Training of Trainers and Implementers}

The SNP task force training subcommittee was responsible for reviewing and revising all required training manuals. The strategy for training in SNP2 was a cascade approach, beginning with training of trainers (TOT) at the district level, who then trained implementers (teachers) at the ward level. This was a shift away from a more centralized model used in SNP1, which required a substantial period of time, as one team of trainers moved from one district and region to another to conduct trainings. The training period for SNP2 was also reduced from a 2-day session to a half-day session at both the district and ward levels. The TOT targeted district malaria focal persons, district school health coordinators for health and education, and the ward education coordinators. The training of implementers was at the ward level, whereby head teachers and school health teachers from all schools within a ward attended the training. The ward education coordinators were the principal trainers who were supervised by national, regional, and district-based staff. Training focused on the use of LLINs, continuous distribution of LLINs through schools, monitoring, and reporting. Participants learned a systematic approach to managing the LLIN distribution process, including handling data collection forms, enumerating students, recording LLIN issuance data, summarizing data, and submitting data.

\section{Social Mobilization}

The IEC/BCC subcommittee of the SNP task force planned advocacy and sensitization meetings; reviewed information, education, and communication (IEC) and behavior change communication (BCC) materials; and trained community change agents and volunteers. The task force distributed IEC materials, and aired radio spots and programs on local radio stations in Ruvuma, Lindi, and Mtwara regions to sensitize the community on the importance of LLIN ownership and use. IEC materials and radio spots focused on the community aspect of LLIN distribution. Spots provided details on the importance of using LLINs, emphasizing that students who received LLINs served as conduits for delivering them to the community.

\section{Development of Tools and Manuals}

The M\&E subcommittee of the SNP task force was set up to revise data collection tools and training manuals. The M\&E team developed registration and issuance booklets as well as summary booklets to capture data at the school level during LLIN issuance. They used the summary booklets, filled in by the school principal, to compare the number of LLINs issued against the number of students in the registration and issuance booklets, filled in by class teachers.

\section{Implementation of the SchoolNet Application}

We developed a database application called SchoolNet to facilitate the collection and management of data from SNP2 schools. The SchoolNet app runs on Android tablets. We trained data clerks to use the SchoolNet app and developed an operative manual for guidance. Data clerks were responsible for entering data from the respective schools onto the tablets. Data were transmitted in real time through the local mobile phone network to a central database where the M\&E team cleaned and analyzed the data in a timely manner for programmatic decision making. This approach to data management reduced the time-lag between LLIN issuance and data reporting, which 
enabled prompt analysis while maintaining high standards of data quality.

\section{Delivery of LLINs}

The logistics subcommittee of the SNP task force was responsible for reviewing the transport and logistics protocols, streamlining distribution procedures, and developing a program and timeline to distribute LLINs from Dar es Salaam to all SNP2 schools. The bulk transportation and distribution of LLINs to schools was led by the Tanzania Red Cross Society (TRCS), a humanitarian organization with expertise in logistics and supply chain management. Moving the LLINs from Dar es Salaam to schools involved geographical reconnaissance, transportation planning, rebundling, storage, and transport to the schools through the districts. TRCS transported LLINs from the central-level medical store department warehouse to the district level, rebundled them according to the quantification data, and stored them in warehouses until distribution to respective SNP2 schools.

\section{Geographical Reconnaissance}

Logistics teams were dispatched to all districts to collect data regarding storage facilities, availability of council and private transports, and maps to design distribution routes. The geographic reconnaissance data were critical to developing a comprehensive logistics and transportation schedule, as it took into account geographical opportunities and challenges, such as poor road infrastructure in hard-to-reach areas.

\section{Rebundling and Transport of LLINS}

Rebundling LLINs involved grouping them into bales according to the needs of each school in the district, based on quantification data gathered during the SNP2 planning phase. TRCS packed LLINs in smaller volumes and labeled each with the quantity of LLINs and the respective school name. Labeled bundles were loaded onto smaller vehicles for ease of access on rural roads to ensure that they reached the targeted schools. To properly account for the LLIN inventory, SNP2 used delivery notes, warehouse journals, and bin cards to document and track net movement at every point of delivery. We conducted an independent procedural audit to track the LLINs from the central warehouse in Dar es Salaam, to a sample of 3 districts warehouses and to a sample of 27 schools. The audit reported that the logistics chain was effective in delivering LLINs and that there were no losses.

\section{LLIN Issuance to Schools and Definition of LLIN Coverage}

LLIN delivery and issuance to all primary and secondary schools took place over a 3-day period on regular school days. Class teachers organized preregistered students by their respective classes. Each student and teacher receiving an LLIN were required to sign against his or her name in the registration and issuance booklets as proof of having received an LLIN. Supervision and documentation focused on the integrity of school data; adherence to procedures for distribution; and feedback on successes, challenges, and areas for improvement related to the LLIN distribution and issuing. We defined LLIN coverage as the proportion of eligible students and teachers who received LLINs.

\section{Data Collection, Management, and Analysis}

With technical assistance and supervision from the M\&E team, data clerks entered data from hard copy training reports, inventory booklets, attendance registers, and school registers in central databases via the SchoolNet app. All information was subjected to periodic data quality checks through regular supervision and review of documents. The head teacher or school principal filled in summary booklets for each school, which the M\&E team used to compare the number of LLINs issued against the number of students registered in each class. The issuance forms also captured the number of LLINs that schools received from the district warehouses, thus enabling the schools to keep track of remaining stocks.

Data from each school were submitted to ward education coordinators for verification and subsequently sent to the district education officers. The M\&E team then verified and cleaned the data. The M\&E team visited all district offices to supervise the data collection process and to verify the quality, tools, and methodology used. To verify the data entered onto the tablets by the data clerks, the M\&E team cross-checked them with hard copies of the issuance forms and summary booklets. All hard copy records were reviewed for accuracy and consistency, and filed in a central repository. Naming conventions were assigned for easy storage and retrieval of the

\section{Issuance forms captured the number of LLINs that schools received, enabling them to track remaining stock.}


Overall, $98 \%$ of eligible students and $96 \%$ of eligible teachers received LLINs in the 3 regions. records on hand. Relevant data were extracted from the SchoolNet app database and exported to a Microsoft Excel spreadsheet for analysis.

The M\&E team used Stata 12.0 to conduct data analysis. The team used descriptive statistics to investigate frequency distributions and proportions, and box plots to investigate the distributions of number of students eligible for SNP by class and region.

\section{Ethical Consideration}

SNP2 was undertaken as part of public health programming, and therefore ethical clearance was not required a priori. The National Health Research Ethics Subcommittee granted written permission to publish these data.

\section{RESULTS}

\section{Training of Trainers and Implementers}

Table 1 shows the number of people trained as trainers and implementers (teachers) in the targeted 19 districts in 3 regions, by gender. Overall, 487 trainers $(78.1 \%$ male) and 4,583 teachers as implementers $(66.8 \%$ male) were trained.

\section{Social Mobilization}

\section{Comprehensive social mobilization activities complemented LLIN distribution, including IEC and BCC materials, radio spots, and sensitization sessions.}

Table 2 shows the number of IEC and BCC materials distributed during SNP2 by region. In addition, 2,600 radio spots and 23 PataPata children's radio programs were broadcast through local radio stations, including Jogoo FM, Pride FM, Newala FM, and the Tanzania Broadcasting Corporation. A total of 4,392 community change agents (434 at the ward level and 3,958 at the village level) delivered 1,500 sensitization and mobilization sessions, reaching 42,626 people.

\section{Participation in the Program}

All 2,337 schools participated in SNP2-targeted districts, the majority of which were primary schools (Table 3 ). The number of schools varied within each district, ranging from 41 in Lindi Municipal Council to 269 in Mbinga District Council. A total of 473,700 students were registered in SNP2 schools and were eligible to participate in the distribution. Primary school students in Standards 1, 3, 5, and 7 comprised $89.3 \%$ of the total number of eligible students. Figure 2 shows the distribution of registered students by region for each grade eligible to receive an LLIN through SNP2. The number of registered students declined in each subsequent grade, with a median of 59 (interquartile range [IQR], 40-83) students in Standard l compared with a median of 34 (IQR, 23-51) students in Standard 7. In secondary schools, the median (IQR) students in Form 2 and Form 4 were 60 (40-97) and 25 (14-49), respectively (Figure 2). A total of 25,269 teachers were registered in all schools (Table 3).

\section{LLINs Issued to Schools and LLIN Coverage} Schools received a total of 507,775 LLINs, of which $91.5 \%$ and $4.8 \%$ were issued to students and teachers, respectively (Table 4). After distribution, $3.7 \%$ of LLINs remained, ranging from $1.7 \%$ in Ruvuma to $5.4 \%$ in Lindi.

Figure 3 shows the distribution of LLIN coverage by grade and region, and Table 4 and Figure 4 shows coverage by district. Overall, 97.9\% of students and $95.8 \%$ of teachers received LLINs in the 3 regions. Mtwara Region had the lowest LLIN coverage for both teachers and students, at $96.6 \%$ and $94.5 \%$, respectively. Across all districts, the percentage of teachers and students that received LLINs was consistently above 90\% (Figure 3 and Figure 4).

\section{DISCUSSION}

The school-based net distribution program, SNP2, successfully issued LLINs to $98 \%$ of eligible students and $96 \%$ of eligible teachers in the 3 targeted regions of Tanzania. Our findings are consistent with a similar pilot study in Ghana where LLINs were distributed to students in grades 2 and 6 of primary schools, teachers, and district office team members, and achieved nearly $100 \%$ LLIN coverage among eligible participants. ${ }^{23}$ Independent evaluations of SNPI and SNP2 in Tanzania found that this school-based approach resulted in increased household ownership and improved usage of LLINs compared with control districts with no school-based delivery mechanism. ${ }^{24,25}$ Following SNP2 implementation, household ownership of LLINs was $84 \%$ in Mtwara, 84\% in Lindi, and 75\% in Ruvuma, and universal coverage of LLINs (households with 1 net for every 2 people) was estimated at $70 \%$ in Mtwara, 65\% in Lindi, and 56\% in Ruvuma. In comparison, universal coverage of LLINs in nonSNP2 control districts in Lake Zone was lower: $33 \%$ in Chato District and $46 \%$ in Sengerema District. ${ }^{25}$ Despite 2 rounds of SNP, coverage of LLINs across the 3 SNP target regions was still below the universal coverage target of $80 \%$. 
TABLE 1. Number of Trainers and Implementers Trained for SNP2, by District and Gender, 2014

\begin{tabular}{|c|c|c|c|c|c|}
\hline \multirow[b]{2}{*}{ Region } & \multirow[b]{2}{*}{ District } & \multicolumn{2}{|c|}{ Trainers } & \multicolumn{2}{|c|}{ Implementers (Teachers) } \\
\hline & & Total & $\%$ Male & Total & $\%$ Male \\
\hline \multirow[t]{6}{*}{ Lindi } & Kilwa District Council & 27 & $96.3 \%$ & 250 & $82.8 \%$ \\
\hline & Lindi District Council & 25 & $80.0 \%$ & 223 & $65.9 \%$ \\
\hline & Lindi Municipal Council & 11 & $54.5 \%$ & 82 & $56.1 \%$ \\
\hline & Liwale District Council & 23 & $82.6 \%$ & 139 & $74.8 \%$ \\
\hline & Nachingwea District Council & 34 & $70.6 \%$ & 258 & $65.5 \%$ \\
\hline & Ruangwa District Council & 23 & $69.6 \%$ & 192 & $65.1 \%$ \\
\hline Subtotal & & 143 & $77.6 \%$ & 1,144 & $69.8 \%$ \\
\hline \multirow[t]{7}{*}{ Mtwara } & Masasi District Council & 26 & $76.9 \%$ & 293 & $65.5 \%$ \\
\hline & Masasi Town Council & 14 & $64.3 \%$ & 90 & $47.8 \%$ \\
\hline & Mtwara District Council & 31 & $80.6 \%$ & 298 & $73.8 \%$ \\
\hline & Mtwara Municipal Council & 18 & $83.3 \%$ & 104 & $58.7 \%$ \\
\hline & Nanyumbu District Council & 17 & $76.5 \%$ & 200 & $73.5 \%$ \\
\hline & Newala District Council & 31 & $74.2 \%$ & 291 & $69.1 \%$ \\
\hline & Tandahimba District Council & 34 & $88.2 \%$ & 289 & $72.0 \%$ \\
\hline Subtotal & & 171 & $78.9 \%$ & 1,565 & $68.5 \%$ \\
\hline \multirow[t]{6}{*}{ Ruvuma } & Mbinga District Council & 44 & $75.0 \%$ & 552 & $59.8 \%$ \\
\hline & Namtumbo District Council & 23 & $95.7 \%$ & 283 & $63.6 \%$ \\
\hline & Nyasa District Council & 21 & $90.5 \%$ & 226 & $78.8 \%$ \\
\hline & Songea District Council & 21 & $76.2 \%$ & 245 & $60.4 \%$ \\
\hline & Songea Municipal Council & 23 & $78.3 \%$ & 230 & $49.6 \%$ \\
\hline & Tunduru District Council & 41 & $82.9 \%$ & 338 & $71.0 \%$ \\
\hline Subtotal & & 173 & $82.1 \%$ & 1,874 & $63.5 \%$ \\
\hline Grand Total & & 487 & $79.7 \%$ & 4,583 & $66.8 \%$ \\
\hline
\end{tabular}

Abbreviation: SNP2, School Net Program - Round 2.

This is largely attributed to the fact that SNP started in 2013, 2 years after the 2011 mass LLIN distribution campaign. Based on NetCALC models, LLIN coverage would have declined by $50 \%$ to $60 \%$ between 2011 and 2013. ${ }^{12,26}$ To maintain universal coverage, we recommend that continuous distribution through SNP should be implemented within 9 to 12 months of any mass LLIN distribution campaign. ${ }^{26}$

Compared with SNP1, SNP2 achieved higher LLIN coverage of students (98\% versus $83 \%$ ), distributed $16 \%$ more nets, and had fewer LLINs 12 months of any remaining after distribution ( $4 \%$ versus $17 \%$ ) due mass distribution to a change in the program design to include campaign. 
TABLE 2. Number of IEC Materials Distributed by SNP2, by District, 2014

\begin{tabular}{lrrrr}
\hline Type of IEC Material & Mtwara & Lindi & Ruvuma & Total \\
\hline Community posters (Tushirikiane Kutokomeza Malaria) & 4,878 & 3,738 & 3,000 & 11,616 \\
School posters (Mwanafunzi Shiriki) & 3,975 & 3,025 & 3,700 & 10,700 \\
Multiplication tables & 64,125 & 45,600 & 70,775 & 180,500 \\
Patapata posters & 3,225 & 2,400 & 3,725 & 9,350 \\
Comic brochures & 166,667 & 166,667 & 166,666 & 500,000 \\
Patapata notebooks & 5,285 & 10,220 & 9,905 & 25,410 \\
Patapata notebooks for radio station & 5 & 5 & 5 & 15 \\
Teacher cue cards & 1,935 & 1,440 & 2,235 & 5,610 \\
Community change agents cue cards (Dondoo za Majadiliano) & 302 & 282 & 284 & 868 \\
\hline
\end{tabular}

Abbreviations: IEC, information, education, and communication; SNP2, School Net Program - Round 2.

\section{Future school- based LLIN distribution should consider targeting primary school students only.}

teachers in all regions and additional grades in Lindi region. SNP2 was built on effective collaboration and teamwork between the Ministry of Health and Social Welfare, local government, and implementing partners. Specific roles and responsibilities were assigned to working groups to implement elements of the SNP frameworka crucial ingredient for the success of SNP2 activities, as demonstrated in previous campaigns conducted in Tanzania. ${ }^{8,11}$ Some adjustments were made to the pilot SNP1 approach, which also contributed to SNP2's success. These included (1) providing training to the trainers and implementers; (2) implementing comprehensive social mobilization activities ${ }^{12,25}$; (3) introducing the SchoolNet app, enabling real-time data entry into a central database, more effective data management, feedback on data quality, and easier and more timely data analysis and dissemination; and (4) timing the LLIN distribution in August (i.e., during the dry season) to ensure easier access to all schools for LLIN delivery.

Slight differences between school enrollment data provided by districts (used for quantification) and student registration at schools (recorded in real time during issuing) may have resulted in a deficit or oversupply of LLINs in a small proportion of schools. Such deficits were resolved through redistribution of excess LLINs from neighboring schools. We therefore recommend that head teachers should provide school enrollment data for net quantification. Also, based on feedback from participants, the half-day training for trainers and implementers was not adequate to cover all necessary SNP2 details; trainings should be extended to 1 day in future rounds of the SNP. We also recommend that the training of key implementers (teachers) should be coordinated by the Ministry of Education and Vocational Training, who should be more engaged in SNP. Finally, models have shown that $35 \%$ of households are potentially not reached by either the TNVS or SNP. $^{24}$ Registration data suggest that as students progress to higher grades, dropout rates increase, meaning that in households where all children drop out of school, they will not be eligible to receive LLINs. Thus, while it is expected that some households not eligible for LLINs via the TNVS or SNP could benefit from LLIN redistribution within households, further strategies are needed to ensure universal access to LLINs by the general population. The results of this program show that substantial proportions $(89.3 \%)$ of students eligible for SNP were from primary schools; therefore, future school-based LLIN distribution should consider targeting primary school students only.

\section{CONCLUSION}

SNP2 was successful in reaching $98 \%$ of eligible students and $96 \%$ of eligible teachers in 3 regions 
TABLE 3. Schools, Eligible Students, and Teachers Participating in SNP2, by District, 2014

\begin{tabular}{|c|c|c|c|c|c|c|c|c|c|c|c|c|c|c|}
\hline \multirow[b]{2}{*}{ Region } & \multirow[b]{2}{*}{ District } & \multicolumn{3}{|c|}{ No. of Schools } & \multicolumn{9}{|c|}{ No. of Students ${ }^{a}$} & \multirow{2}{*}{$\begin{array}{l}\text { No. of } \\
\text { Teachers }\end{array}$} \\
\hline & & Primary & Secondary & Total & Std. 1 & Std. 2 & Std. 3 & Std. 4 & Std. 5 & Std. 7 & Form 2 & Form 4 & Total & \\
\hline \multirow[t]{6}{*}{ Lindi } & Kilwa District Council & 108 & 28 & 136 & 7,483 & 6,283 & 5,925 & 5,631 & 4,604 & 4,255 & 1,448 & 547 & 36,176 & 1,226 \\
\hline & Lindi District Council & 114 & 27 & 141 & 7,364 & 5,972 & 4,965 & 5,420 & 3,987 & 3,428 & 1,428 & 574 & 33,138 & 1,218 \\
\hline & Lindi Municipal Council & 32 & 9 & 41 & 2,421 & 1,937 & 1,853 & 1,766 & 1,567 & 1,358 & 843 & 400 & 12,145 & 619 \\
\hline & Liwale District Council & 54 & 16 & 70 & 4,225 & 3,220 & 2,982 & 3,204 & 2,582 & 2,035 & 1,233 & 309 & 19,790 & 654 \\
\hline & $\begin{array}{l}\text { Nachingwea District } \\
\text { Council }\end{array}$ & 103 & 26 & 129 & 6,302 & 5,890 & 4,769 & 4,299 & 3,860 & 3,192 & 1,755 & 428 & 30,495 & 1,222 \\
\hline & $\begin{array}{l}\text { Ruangwa District } \\
\text { Council }\end{array}$ & 82 & 15 & 97 & 4,301 & 3,829 & 3,144 & 3,526 & 2,468 & 2,119 & 873 & 313 & 20,573 & 886 \\
\hline Subtotal & & 493 & 121 & 614 & 32,096 & 27,131 & 23,638 & 23,846 & 19,068 & 16,387 & 7,580 & 2,571 & 152,317 & 5,825 \\
\hline \multirow[t]{7}{*}{ Mtwara } & Masasi District Council & 126 & 23 & 149 & 8,645 & & 6,838 & & 6,024 & 5,439 & 1,863 & 1,156 & 29,965 & 1,588 \\
\hline & Masasi Town Council & 37 & 8 & 45 & 3,130 & & 2,214 & & 1,776 & 2,003 & 888 & 410 & 10,421 & 714 \\
\hline & Mtwara District Council & 127 & 24 & 151 & 8,253 & & 7,201 & & 5,879 & 5,108 & 1,304 & 457 & 28,202 & 1,360 \\
\hline & $\begin{array}{l}\text { Mtwara Municipal } \\
\text { Council }\end{array}$ & 33 & 21 & 54 & 3,232 & & 2,641 & & 2,394 & 2,096 & 2,079 & 915 & 13,357 & 1,112 \\
\hline & $\begin{array}{l}\text { Nanyumbu District } \\
\text { Council }\end{array}$ & 87 & 11 & 98 & 6,804 & & 4,532 & & 3,577 & 2,631 & 1,053 & 152 & 18,749 & 885 \\
\hline & Newala District Council & 118 & 28 & 146 & 6,175 & & 4,963 & & 5,207 & 4,087 & 1,740 & 534 & 22,706 & 1,419 \\
\hline & $\begin{array}{l}\text { Tandahimba District } \\
\text { Council }\end{array}$ & 115 & 28 & 143 & 7,852 & & 6,964 & & 5,998 & 5,007 & 1,630 & 506 & 27,957 & 1,485 \\
\hline Subtotal & & 643 & 143 & 786 & 44,091 & & 35,353 & & 30,855 & 26,371 & 10,557 & 4,130 & 151,357 & 8,563 \\
\hline \multirow[t]{6}{*}{ Ruvuma } & Mbinga District Council & 227 & 52 & 279 & 11,583 & & 8,815 & & 9,078 & 7,833 & 3,634 & 1,745 & 42,688 & 2,601 \\
\hline & $\begin{array}{l}\text { Namtumbo District } \\
\text { Council }\end{array}$ & 108 & 29 & 137 & 7,505 & & 5,980 & & 5,131 & 4,526 & 2,060 & 1,077 & 26,279 & 1,561 \\
\hline & Nyasa District Council & 97 & 18 & 115 & 5,721 & & 4,594 & & 4,235 & 3,197 & 1,116 & 534 & 19,397 & 964 \\
\hline & Songea District Council & 95 & 27 & 122 & 6,086 & & 5,168 & & 4,393 & 3,715 & 1,776 & 820 & 21,958 & 1,647 \\
\hline & $\begin{array}{l}\text { Songea Municipal } \\
\text { Council }\end{array}$ & 78 & 37 & 115 & 7,547 & & 5,740 & & 5,234 & 4,557 & 3,664 & 1,985 & 28,727 & 2,365 \\
\hline & Tunduru District Council & 146 & 23 & 169 & 10,887 & & 5,889 & & 5,902 & 4,944 & 2,370 & 985 & 30,977 & 1,743 \\
\hline Subtotal & & 751 & 186 & 937 & 49,329 & & 36,186 & & 33,973 & 28,772 & 14,620 & 7,146 & 170,026 & 10,881 \\
\hline \multicolumn{2}{|c|}{ Grand Total } & 1,887 & 450 & 2,337 & 125,516 & 27,131 & 95,177 & 23,846 & 83,896 & 71,530 & 32,757 & 13,847 & 473,700 & 25,269 \\
\hline
\end{tabular}

Abbreviation: SNP2, School Net Program - Round 2.

a Standard 2 and Standard 4 students were eligible for SNP2 in Lindi region only.

in Tanzania. Effective partnerships, coordination, and teamwork facilitated the successful implementation of SNP2. LLIN ownership and use in the community is expected to increase and therefore reduce the burden of malaria in the 3 regions. This program can serve as a model for other countries who wish to implement a schoolbased approach as a keep-up strategy to maintain 
FIGURE 2. Distribution of Registered Students Eligible to Receive a Long-Lasting Insecticidal Net, by Class and Region

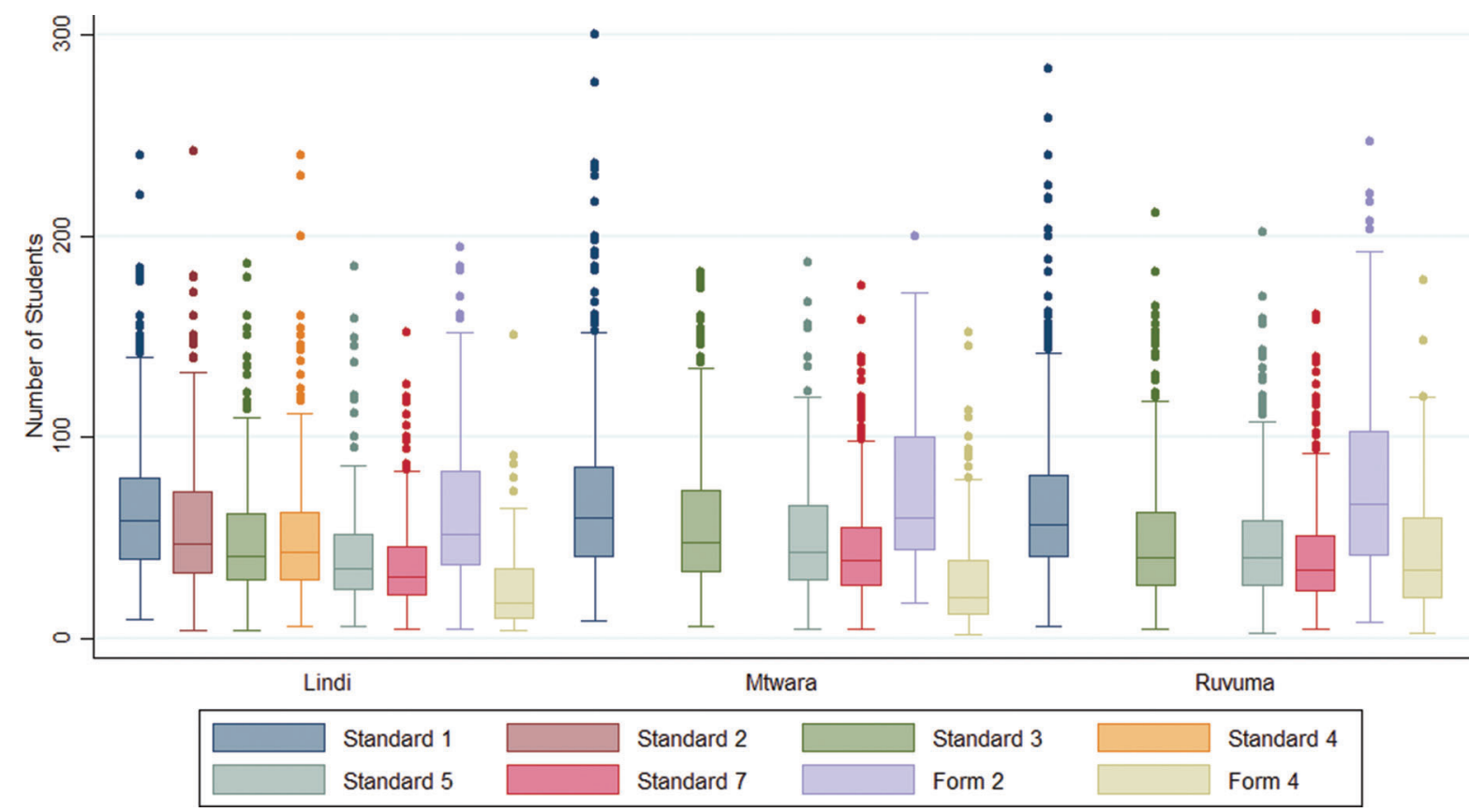

FIGURE 3. Percentage of Eligible Students and Teachers Receiving a Long-Lasting Insecticidal Net, by Class and Region

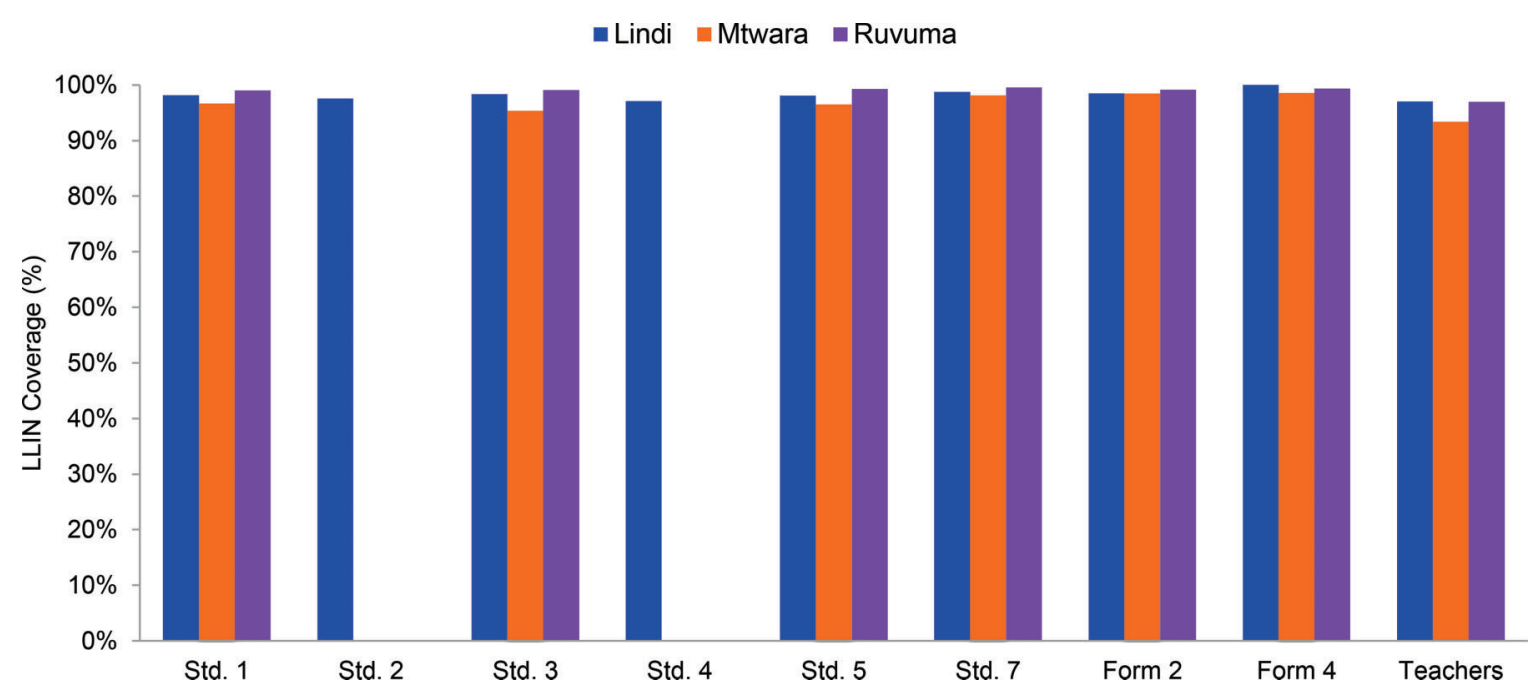


TABLE 4. LLINs Issued to Teachers and Students by SNP2, by District, 2014

\begin{tabular}{|c|c|c|c|c|c|c|c|c|c|}
\hline \multirow[b]{2}{*}{ Region } & \multirow[b]{2}{*}{ District } & \multicolumn{5}{|c|}{ No. of LIINs: } & \multicolumn{3}{|c|}{ Percentage of: } \\
\hline & & $\begin{array}{l}\text { Received } \\
\text { by School }\end{array}$ & $\begin{array}{l}\text { Issued to } \\
\text { Students }\end{array}$ & $\begin{array}{l}\text { Issued to } \\
\text { Teachers }\end{array}$ & $\begin{array}{l}\text { Total } \\
\text { Issued }\end{array}$ & $\begin{array}{l}\text { Remaining } \\
\text { After Issuing }\end{array}$ & $\begin{array}{l}\text { Registered Students } \\
\text { Issued LLINs }\end{array}$ & $\begin{array}{l}\text { Registered Teachers } \\
\text { Issued LLINs }\end{array}$ & $\begin{array}{l}\text { LLINs } \\
\text { Remaining }\end{array}$ \\
\hline \multirow[t]{6}{*}{ Lindi } & Kilwa District Council & 35,575 & 35,702 & 1,206 & 36,781 & 1,903 & $98.3 \%$ & $98.4 \%$ & $4.6 \%$ \\
\hline & Lindi District Council & 32,425 & 32,451 & 1,195 & 33,620 & 4,195 & $97.9 \%$ & $98.1 \%$ & $11.0 \%$ \\
\hline & Lindi Municipal Council & 11,853 & 11,901 & 619 & 12,472 & 200 & $97.7 \%$ & $100.0 \%$ & $1.2 \%$ \\
\hline & Liwale District Council & 19,730 & 19,807 & 653 & 20,383 & 461 & $99.7 \%$ & $99.8 \%$ & $1.8 \%$ \\
\hline & $\begin{array}{l}\text { Nachingwea District } \\
\text { Council }\end{array}$ & 29,555 & 29,660 & 1,112 & 30,667 & 421 & $96.7 \%$ & $91.0 \%$ & $1.0 \%$ \\
\hline & $\begin{array}{l}\text { Ruangwa District } \\
\text { Council }\end{array}$ & 20,194 & 20,194 & 868 & 21,062 & 1,993 & $98.2 \%$ & $98.0 \%$ & $8.6 \%$ \\
\hline Subtotal & & 149,332 & 149,715 & 5,653 & 154,985 & 9,173 & $98.0 \%$ & $97.0 \%$ & $5.4 \%$ \\
\hline \multirow[t]{7}{*}{ Mtwara } & Masasi District Council & 28,932 & 28,932 & 1,501 & 30,433 & 2,740 & $96.5 \%$ & $94.5 \%$ & $8.3 \%$ \\
\hline & Masasi District Council & 10,095 & 10,095 & 664 & 10,759 & 175 & $96.6 \%$ & $93.0 \%$ & $1.6 \%$ \\
\hline & Mtwara District Council & 26,896 & 26,896 & 1,266 & 28,162 & 719 & $95.3 \%$ & $93.1 \%$ & $2.5 \%$ \\
\hline & $\begin{array}{l}\text { Mtwara Municipal } \\
\text { Council }\end{array}$ & 13,244 & 13,244 & 1,050 & 14,294 & 100 & $98.8 \%$ & $94.4 \%$ & $0.7 \%$ \\
\hline & $\begin{array}{l}\text { Nanyumbu District } \\
\text { Council }\end{array}$ & 18,681 & 18,681 & 878 & 19,559 & 1,384 & $99.6 \%$ & $99.2 \%$ & $6.6 \%$ \\
\hline & Newala District Council & 22,314 & 22,314 & 1,322 & 23,636 & 1,185 & $98.0 \%$ & $93.2 \%$ & $4.8 \%$ \\
\hline & $\begin{array}{l}\text { Tandahimba District } \\
\text { Council }\end{array}$ & 26,310 & 26,310 & 1,317 & 27,627 & 508 & $93.8 \%$ & $88.7 \%$ & $1.8 \%$ \\
\hline Subtotal & & 146,472 & 146,472 & 7,998 & 154,470 & 6,811 & $96.6 \%$ & $93.4 \%$ & $4.2 \%$ \\
\hline \multirow[t]{6}{*}{ Ruvuma } & Mbinga District Council & 42,380 & 42,380 & 2,550 & 44,930 & 670 & $99.2 \%$ & $98.0 \%$ & $1.5 \%$ \\
\hline & $\begin{array}{l}\text { Namtumbo District } \\
\text { Council }\end{array}$ & 26,133 & 26,133 & 1,483 & 27,616 & 393 & $99.2 \%$ & $95.0 \%$ & $1.4 \%$ \\
\hline & Nyasa District Council & 19,281 & 19,281 & 943 & 20,224 & 98 & $99.3 \%$ & $97.8 \%$ & $0.5 \%$ \\
\hline & Songea District Council & 21,525 & 21,525 & 1,584 & 23,109 & 607 & $97.9 \%$ & $96.2 \%$ & $2.6 \%$ \\
\hline & $\begin{array}{l}\text { Songea Municipal } \\
\text { Council }\end{array}$ & 28,689 & 28,689 & 2,365 & 31,054 & 1,074 & $99.9 \%$ & $100.0 \%$ & $3.3 \%$ \\
\hline & Tunduru District Council & 30,698 & 30,698 & 1,630 & 32,328 & 233 & $98.8 \%$ & $93.5 \%$ & $0.7 \%$ \\
\hline \multicolumn{2}{|l|}{ Subtotal } & 168,706 & 168,706 & 10,555 & 179,261 & 3,075 & $99.1 \%$ & $97.0 \%$ & $1.7 \%$ \\
\hline \multicolumn{2}{|c|}{ Grand Total } & 507,775 & 464,510 & 24,206 & 488,716 & 19,059 & $97.9 \%$ & $95.8 \%$ & $3.7 \%$ \\
\hline
\end{tabular}


FIGURE 4. Percentage of Eligible Students and Teachers Receiving a Long-Lasting Insecticidal Net, by District and Region

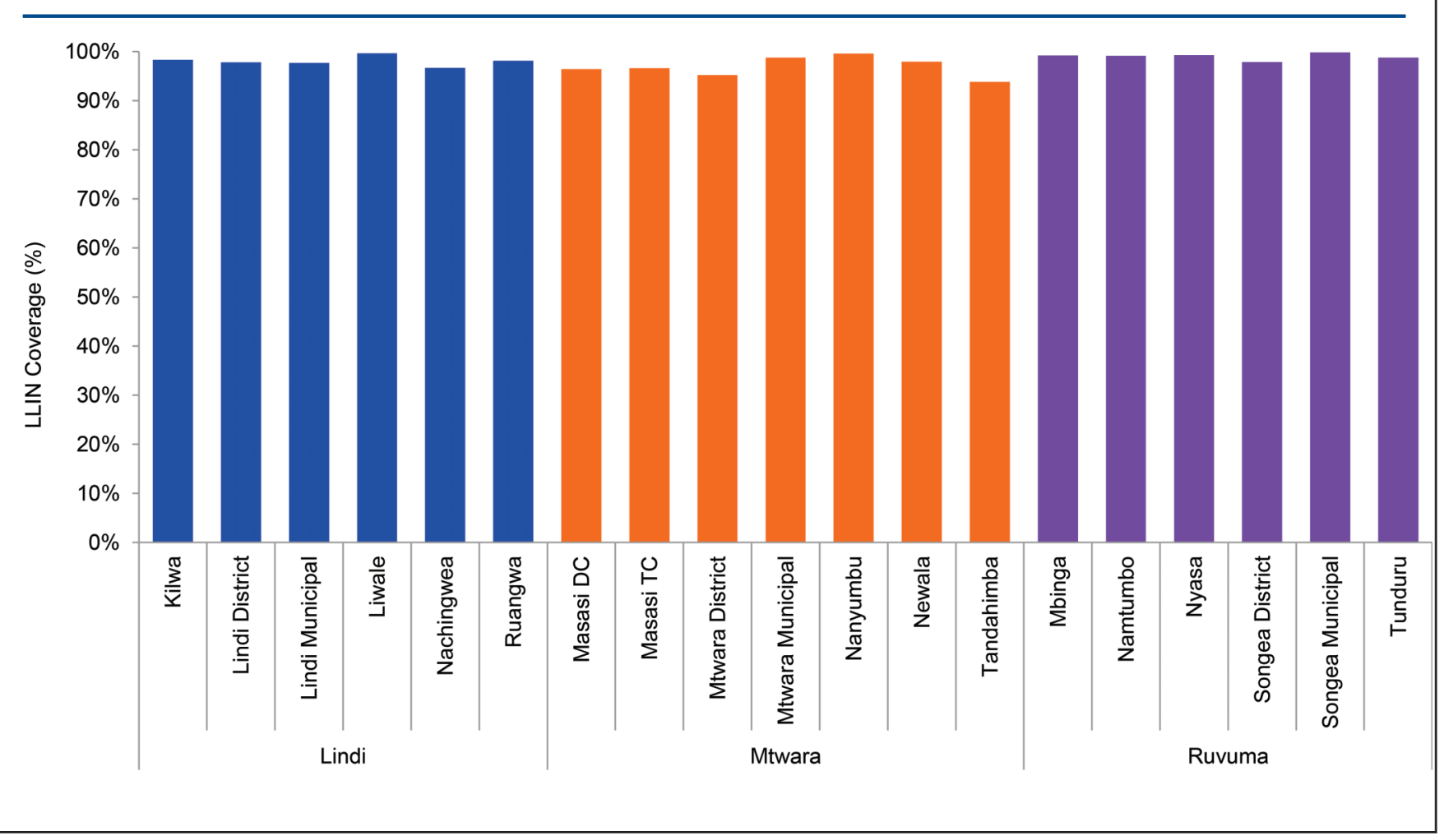

universal coverage of LLINs for malaria prevention and control.

Acknowledgments: We would like to acknowledge members from the Ministry of Health and Social Welfare, Ministry of Education and Vocational Training, and the Prime Minister's Office, Regional Authority and Local Government for their involvement and continuous support during SNP2. We would also like to acknowledge the contribution of schools' district and ward education officers, school teachers, and Tanzania Red Cross Society (TRCS) volunteers in SNP2. We thank the Johns Hopkins Center for Communication Programs and Population Services International (PSI) for leading social mobilization activities. We are grateful to John Snow, Inc. and the medical store department for LLIN logistics as well as PSI and TRCS for their support during advocacy activities. This work was supported by the President's Malaria Initiative via the United States Agency for International Development (USAID) and an interagency agreement with the U.S. Centers for Disease Control and Prevention (CDC). The opinions expressed herein are those of the author(s) and do not necessarily reflect the views of USAID, CDC or other employing organizations or sources of funding.

Competing Interests: None declared.

\section{REFERENCES}

1. Curtis CF, Maxwell CA, Magesa SM, Rwegoshora RT, Wilkes TJ. Insecticide-treated bed-nets for malaria mosquito control. J Am Mosq Control Assoc. 2006;22(3):501-506. CrossRef. Medline
2. Lengeler $C$. Insecticide-treated bed nets and curtains for preventing malaria. Cochrane Database Syst Rev. 2004;(2): CD000363. CrossRef. Medline

3. Roll Back Malaria/World Health Organization. The Abuja declaration and the plan of action. Geneva: Roll Back Malaria Partnership Secretariat, World Health Organization; 2000. Available from: http://apps.who.int/iris/bitstream/10665/ 67816/1/WHO_CDS_RBM_2003.46.pdf

4. World Health Organization. Insecticide-treated mosquito nets: a WHO position statement. Geneva: World Health Organization Global Malaria Programme; 2007. Available from: http://files. givewell.org/files/DWDA\%202009/Interventions/Nets/ itnspospaperfinal.pdf

5. National Malaria Control Programme [Tanzania]. Medium term strategic plan 2008-2013. Dar es Salaam (Tanzania): National Malaria Control Programme; 2008.

6. Mushi AK, Schellenberg JRMA, Mponda $\mathrm{H}$, Lengeler $\mathrm{C}$. Targeted subsidy for malaria control with treated nets using a discount voucher system in Tanzania. Health Policy Plan. 2003; 18(2):163-171. CrossRef. Medline

7. Magesa SM, Lengeler C, de Savigny D, Miller JE, Njau RJA, Kramer K, et al. Creating an "enabling environment" for taking insecticide treated nets to national scale: the Tanzanian experience. Malar J. 2005;4:34. CrossRef. Medline

8. Njau RJA, de Savigny D, Gilson L, Mwageni E, Mosha FW. Implementation of an insecticide-treated net subsidy scheme 
under a public-private partnership for malaria control in Tanzania--challenges in implementation. Malar J. 2009; 8:201. CrossRef. Medline

9. Marchant T, Schellenberg D, Nathan R, Armstrong-Schellenberg J, Mponda $\mathrm{H}$, Jones $\mathrm{C}$, et al. Assessment of a national voucher scheme to deliver insecticide-treated mosquito nets to pregnant women. CMAJ. 2010;182(2):152-156. CrossRef. Medline

10. Mulligan JA, Yukich J, Hanson K. Costs and effects of the Tanzanian national voucher scheme for insecticide-treated nets. Malar J. 2008;7:32. CrossRef. Medline

11. Renggli S, Mandike R, Kramer K, Patrick F, Brown NJ, McElroy PD, et al. Design, implementation and evaluation of a national campaign to deliver 18 million free long-lasting insecticidal nets to uncovered sleeping spaces in Tanzania. Malar J. 2013;12:85. CrossRef. Medline

12. Koenker HM, Yukich JO, Mkindi A, Mandike R, Brown N, Kilian A, et al. Analysing and recommending options for maintaining universal coverage with long-lasting insecticidal nets: the case of Tanzania in 2011. Malar J. 2013;12:150. CrossRef. Medline

13. Bonner K, Mwita A, McElroy PD, Omari S, Mzava A, Lengeler C, et al. Design, implementation and evaluation of a national campaign to distribute nine million free LLINs to children under five years of age in Tanzania. Malar J. 2011;10:73. CrossRef. Medline

14. Tanzania Commission for AIDS (TACAIDS); Zanzibar AIDS Commission (ZAC), National Bureau of Statistics (NBS); Office of the Chief Government Statistician (OCGS); ICF International. Tanzania HIV/AIDS and malaria indicator survey 2011-12. Dar es Salaam (Tanzania): TACAIDS; 2013. Co-published by ZAC, NBS, OCGS, and ICF International. Available from: https:// dhsprogram.com/pubs/pdf/AIS1 1/AIS1 1.pdf

15. Grabowsky M, Nobiya T, Selanikio J. Sustained high coverage of insecticide-treated bednets through combined Catch-up and Keep-up strategies. Trop Med Int Health. 2007;12(7):815-822. CrossRef. Medline

16. Roll Back Malaria, Vector Control Working Group. Continuous long-lasting insecticidal net distributions: a guide to concepts and planning. Geneva: Roll Back Malaria Partnership Secretariat, World Health Organization; 2011. Available from: http://www. rollbackmalaria.org/files/files/partnership/wg/wg_itn/docs/ ws3/3-Guide_to_continuous_distribution_strategy.pdf

17. Sexton AR. Best practices for an insecticide-treated bed net distribution programme in sub-Saharan eastern Africa. Malar J. $2011 ; 10: 157$. CrossRef. Medline
18. Johns Hopkins Center for Communication Programs (CCP), NetWorks project. Continuous LLIN distribution: piloting school net distribution in mainland Tanzania. Lessons in Brief, No. 9. Baltimore (MD): CCP; [2014]. Available from: https://www. k4health.org/sites/default/files/tanzania_llin_9_new.pdf

19. RTI International, Tanzania Vector Control Scale-up Project. School net program performance report: March 28-December 30, 2014. Research Triangle Park (NC): RTI International; 2014.

20. RTI International. LLIN school distribution keep-up campaign, Tanzania: monitoring and evaluation plan. Research Triangle Park (NC): RTI International; 2014.

21. National Bureau of Statistics (NBS) [Tanzania]; Office of Chief Government Statistician (OCGS). 2012 population and housing census: population distribution by administrative areas. Dar es Salaam (Tanzania): NBS; 2013. Co-published by OGCS. Available from: http://ihi.eprints.org/1344

22. National Bureau of Statistics (NBS) [Tanzania]; ICF Macro. Tanzania demographic and health survey 2010. Dar es Salaam (Tanzania): NBS; 2011 . Co-published by ICF Macro. Available from: http://dhsprogram.com/pubs/pdf/FR243/FR243\% 5B24June2011\%5D.pdf

23. Zegers de Beyl C, Asamoah OE, Ato Selby R. Report of the process evaluation of the continuous LLIN distribution system in Ghana. Baltimore (MD): Johns Hopkins Center for Communication Programs; 2013. Available from: https://www. k4health.org/sites/default/files/report_-_process_evaluation_ of_eastern_region_llin_continuous_distribution_pilot_0.pdf

24. Nathan R, Kalage R, Lutambi A. Evaluation of School Net Pilot Project in the Southern zone: final report. Dar es Salaam (Tanzania): Ifakara Health Institute; 2013.

25. Lutambi A, Nathan R, Chacky F, Mandike R, Kramer K, Masanja $\mathrm{H}$, et al. School-based LLIN distribution in Tanzania: results of repeated cross-sectional surveys. Presented at the 64th ASTMH meeting; 2015 Oct 28; Philadelphia, Pennsylvania. Abstract available from: http://www.abstractsonline.com/Plan/ ViewAbstract.aspx? sKey=dd7fcf42-c32f-48f1-82bf-2b4738 ac71 1 b\&cKey=e285f334-0672-4b94-92f9-34d015bec7d9 \&mKey=ab652fdf-01 11 -45c7-a5e5-0ba9d4af5el 2

26. National Insecticide Treated Nets (NATNETS)-Tanzania [Internet]. Dar es Salaam (Tanzania): National Malaria Control Programme, NATNETS; c2012-2015. School Net Programme; [cited 2016 Apr 1]. Available from: http://www.natnets.org/ index.php/programme-components/school-net-programme. html.

\section{Peer Reviewed}

\section{Received: 2016 Feb 9; Accepted: 2016 Apr 20}

Cite this article as: Lalji S, Ngondi JM, Thawer NG, Tembo A, Mandike R, Mohamed A, et al. School distribution as keep-up strategy to maintain universal coverage of long-lasting insecticidal nets: implementation and results of a program in southern Tanzania. Glob Health Sci Pract. 2016;4(2):251-263. http://dx.doi.org/10.9745/GHSP-D-16-00040

(c) Lalji et al. This is an open-access article distributed under the terms of the Creative Commons Attribution License, which permits unrestricted use, distribution, and reproduction in any medium, provided the original author and source are properly cited. To view a copy of the license, visit $\mathrm{http}: / /$ creativecommons.org/licenses/by/3.0/. When linking to this article, please use the following permanent link: http://dx.doi.org/ 10.9745/GHSP-D-16-00040 